\title{
A test of equilibrium theory: Visual interaction in relation to orientation, distance and sex of interactants*
}

\author{
JOHN R. AIELLO \\ Michigan State University, East Lansing, Mich. 48823
}

In a test of an equilibrium theory of social interaction, (1) females were found to engage in more visual interaction than males; (2) while a linear relationship between distance and amount of "looking" and average glance length was obtained for males at two orientations, a curvilinear relationship between these variables was found for females in a face-to-face orientation, and (3) Ss, especially females, maintained longer glances when face to face.

Recent experiments, summarized by Argyle (1969), have shown that the physical distance between two interactants, and the frequency and duration with which they look into the region of each other's eyes, are important parameters of their social interaction. Argyle \& Dean (1965) postulated that approach and avoidance forces produce an equilibrium level between these and other variables related to social intimacy. Sex differences (Exline, 1963; Exline et al, 1965), as well as the degree of orientation maintained between interactants (Sommer, 1961, 1965), have also been found to be related to proximity and visual behavior. The purpose of the present study is to examine the effects of physical distance, body orientation, and sex of interactants on visual interaction.

In addition to providing the first empirical test of the relationship among these aspects of intimacy taken together, this study overcomes several methodological problems encountered in previous research in this area. Most studies have employed $100 \%$ gaze direction by confederates; this behavior could be viewed as very unnatural and obtrusive by $S$ (Duncan, 1969). In the present study, the author wanted to avoid using this behavior and therefore chose to study S's amount of "looking" in the region of the confederate's eyes rather than eye contact (mutual "looking"). While it was realized that some control would be lost because confederate's visual behavior was not regulated, it was believed that the resulting gain from the more "natural" atmosphere for both Ss and confederates would provide greater generalizability of the findings. Also, previous investigations (cf. Argyle \& Dean, 1965) used a

* This study was supported in part by NIMH Grant MH-10779-04. A paper based on these data was presented at the 1972 meeting of the Midwestern Psychological Association. procedure in which Ss were asked to move their seats to different positions during the experiment to establish the effects of the varying distances under study. This procedure has been criticized because as the distance between $S$ and confederate changed, so too did the distance between $S$ and $O$ change; that is, as the distance becomes greater between Os and Ss, Os find it more difficult to distinguish when Ss are looking into the region of the confederate's eyes and increasingly record as "looking" peripheral visual directions (Stephenson \& Rutter, 1970). This study resolved this problem by having the confederate assume the various seats to establish the experimental positions, thus leaving the judging distance between $S$ and $O$ the same across conditions.

$$
\text { METHOD }
$$

The Ss were 51 males and 54 females enrolled in introductory psychology classes at Michigan State University. The students were given course credit for their participation, and they reported individually for the experiment.

The experiment was conducted in a room, $16.5 \times 8.0 \mathrm{ft}$, with small one-way mirrors located $3 \frac{1 / 2}{\mathrm{ft}}$ from the floor on three of the four walls. Three rectangular tables, $2.5 \times 5.0 \mathrm{ft}$, were placed in the room to provide greater control in the maintenance of the six experimental positions between confederates and Ss.

When a $S$ arrived for the experiment, he was escorted into the experimental room by one of two male or one of two female confederates, who assumed a seat 2,6 , or $10 \mathrm{ft}$ from the $S$ and sat either directly across the table from the $S$ (0 deg) or at a right angle to him (90 deg).

During the interview, confederates maintained whatever visual behavior was natural to them; the only imposed rule was that they speak approximately $50 \%$ of the time during the experimental interval, so as to overcome possible bias resulting from the natural tendency of listeners to look a greater percentage of the time (Kendon, 1967). The experimental intervals contained a topic which was pretested to be interesting but neutral to Ss (i.e., volunteer army). Three minutes of "acquaintance" preceded the 3 -min experimental interval; during the preface period, the confederate introduced himself and the topic of conversation and exchanged such information as "major field of study" with the $S$ in an attempt to facilitate subsequent conversation. The total length of the interview period was about $12 \mathrm{~min}$.

The S's visual behavior was measured by using a procedure similar to that described by Goldberg et al (1969); S's and confederate's verbal behaviors were also measured for the purpose described above. After five $2 \cdot h$ training sessions, inter- $O$ reliabilities for the four judges measuring S's visual behavior exceeded .96 , and reliabilities of the five judges measuring S's and confederate's verbal behaviors exceeded .98 .

\section{RESULTS}

The results were analyzed in a 2 by 2 by 3 by 2 unequal-cell multivariate ANOVA design. Female Ss were found to look in the region of the confederate's eyes more than male Ss $(F=6.04$, df $=1 / 81, p<.02)$. A significant interaction between sex of $S$ and distance was found to exist for both independent variables, amount of looking and average glance length $(F=$ $4.09, \mathrm{df}=1 / 81, \mathrm{p}<.03, \mathrm{~F}=3.35, \mathrm{df}$ $=1 / 81, p<.04)$. As Fig. 1 shows, while amount of looking and length of glance increased linearly with distance for male Ss, a curvilinear relationship was found for female Ss, such that amount of looking and length of glances increased between $2 \mathrm{ft}$ and $6 \mathrm{ft}$, but then decreased between $6 \mathrm{ft}$ and $10 \mathrm{ft}$. A significant interaction was also found between sex of $S$ and sex of confederate; male Ss looked more with male confederates and female Ss looked more with female confederates $(F=6.03, \mathrm{df}=1 / 81, \mathrm{p}<.02)$. Body orientation significantly affected the length of S's glances so that glances were longer when Ss were face to face with confederates $(\mathrm{F}=4.37, \mathrm{df}=$ $1 / 81, \mathrm{p}<.04$ ).

\section{DISCUSSION}

As predicted by the equilibrium model and found by Argyle \& Dean (1965), both males and females, when seated at right angles (90-deg orientation), looked progressively more as distance between $\mathrm{Ss}$ and confederates increased. This linear trend continued for males in the face-to-face condition, but a curvilinear relationship was found to exist for females at the more direct 


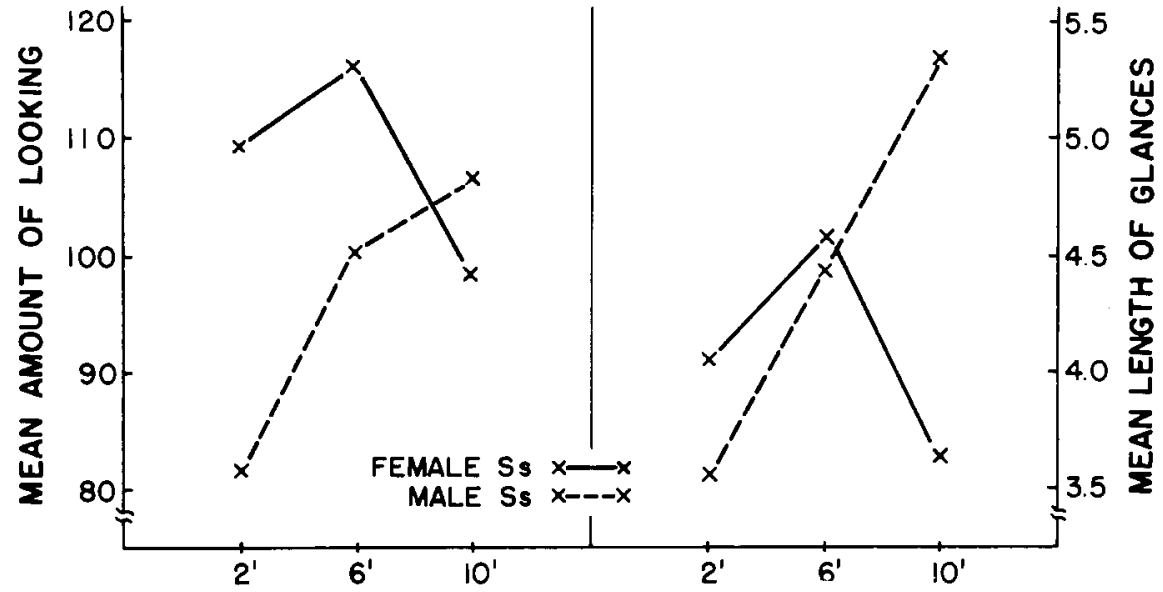

Fig. 1. Mean amount of looking and length of glances (in seconds) by male and female Ss at three distances.

angle, such that "looking" at the far distance declined to a level below that maintained at the closest distance (see Fig. 1). It may be that as Exline (1963, p. 18) stated, "Women's visual activity is not only more likely to be oriented toward social stimuli than men's, but it is also more affected by relevant social field conditions." In this case, the large distance, while comfortable for men, appears to have lacked necessary reinforcement value for women, especially in the more direct orientation where a greater "availability" for interaction exists. This finding, at the very least, implies a differential upper boundary between the sexes for orientation and distance effects on the visual interaction necessary to maintain equilibrium; further testing of these boundary conditions is needed to refine the theory.
With the exception noted above, women typically looked more than men; this finding is consonant with previous studies (cf. Exline, 1963). Consistent with the results of Argyle \& Dean (1965), greater looking occurred between members of same-sex pairs. This could have ensued because male Ss were more comfortable with the relatively lower level of "looking" from male confederates and female Ss were comfortable with the higher level of "looking", from female confederates. But as is more likely, by Argyle \& Dean (1965), where confederates stared $100 \%$ of the time, the initial encounter of opposite-sex pairs at this age is a more anxiety-arousing situation for Ss, thus producing a blockage of approach forces and resulting in less preludial intimacy. Further study of this process especially in light of similar findings over longer periods of time and in other situations might well result in very different findings and should be explored.

In conclusion, an equilibrium theory of social interaction was only partially supported in this experiment. The lack of upper boundaries for the variables which are involved in the intimacy equation (in this study, distance) was found to be a definite weakness of the theory, as it is presently proposed. Also, it appears as though males and females have very different equilibrium behaviors; differentiation as to the sex of Ss should continue to be made in future tests of this theory.

\section{REFERENCES}

ARGYLE, M. Social interaction. New York A therton Press, 1969.

ARGYLE, M., \& DEAN. J. Eye contact, distance, and affiliation. Sociometry, 1965. 28, 289-304.

DUNCAN. S. Nonverbal communication Psychological Bulletin. 1969, 72. 118-137.

EXLINE. R. V. Explorations in the process of person perception: Visual interaction in relation to competition, sex, and need for affiliation. Journal of Personality. $1963,31,1-20$

EXLINE, R. V., GRAY. D., \& SCHUETTE. D. Visual behavior in a dyad as affected by interview content and sex of respondent. Journal of Personality \& Social Psychology, 1965, 1, 201-209.

GOLDBERG, G., KIESLER. C., \& COLLINS. B. Visual behavior and face-to-face distance during interaction. Sociometry, 1969, 32, 43-53.

KENDON. A. Some functions of gaze-directions in social interaction. Acta Psychologica, 1967, 26, 22-63.

SOMMER, $R$. Leadership and group geography. Sociometry, 1961, 24. 99-110.

SOMMER, R. Further studies of small group ecology. Sociometry, 1965, 28, 337-348. STEPHENSON, G.. \& RUTTER. D. Eye-contact, distance, and affiliation: A re-evaluation. British Journal of Psychology, 1970,61, 385-393. 